\title{
Leer para escribir, aporte de la escritura creativa (notas a mano alzada)
}

Fecha de recepción: 21 de Agosto de 2018

Desde el año 2007, cuando se da inicio a la Maestría en Escrituras Creativas de la Universidad Nacional de Colombia, he trabajado como coordinadora de la línea de narrativa y he tenido a mi cargo, junto con otros colegas, la enseñanza en los talleres de primer y segundo semestre. Es decir, que en mi experiencia como profesora he desarrollado técnicas para el aprendizaje de las técnicas narrativas, especialmente en la forma en que nuestros estudiantes pueden encontrar la estructura de sus novelas y cuentos. He dado talleres de escritura en otras universidades como la Central en Bogotá y la Universidad Humboldt en Berlín, y con otras instituciones como el British Council, donde coordino el componente académico del programa Elipsis de formación de jóvenes escritores. Estas experiencias me han llevado a pensar los aportes que hace la escritura creativa al conocimiento académico contemporáneo en el área de la literatura, y por tanto quiero presentarles algunas reflexiones sobre los impactos que tiene en la lectura. La lectura para escribir alimenta, desde mi perspectiva, la lectura general de la literatura y eso es lo que quiero compartirles.

En el año 2015, en el Hay Festival en Cartagena, tuve la oportunidad de tener una conversación pública con la escritora Almudena Grandes. En ese momento, la escritora se quejó de la lectura tan superficial que hacen la mayoría de los críticos literarios y las personas

Citar: Jaramillo Morales, A. (enero-junio de 2019). Leer para escribir, aporte de la escritura creativa (notas a mano alzada). La Palabra, (34), 133-138. Go https://doi. org/10.19053/01218530.n34.2019.9537

\section{Alejandra Jaramillo Morales}

Escritora y profesora asociada Maestría en Escrituras Creativas Universidad Nacional de Colombia.

alejaramillomo@gmail.com 
que comentan libros, porque se quedan demasiado en los temas tratados en los libros, y no en las formas cómo se desarrollan esos temas. Encontrar el cómo contar una historia, cómo desarrollar un tema desde la literatura es lo más importante que hace un escritor o escritora y eso, decía Grandes, no es precisamente lo principal que miran los lectores, los críticos o los periodistas. Almudena Grandes contaba que ella normalmente pasa año y medio o más durante la preparación de un libro, en lo que llama "etapa de cuaderno". Es decir, un largo período en que toma notas y va construyendo la estructura de la obra que va a escribir.

Eso que Almudena Grandes llama la "etapa de cuaderno", es la impronta principal que todo escritor o escritora le da a un texto. Pues como ya lo decía Jorge Luis Borges en su ensayo "La esfera de Pascal" (1996), la historia de la humanidad está hecha de pocas metáforas, es decir que los temas de los que habla en la literatura no son muchos, más bien se multiplican porque cada autor descubre una nueva forma de contarlos, de observarlos, de hacer que sus personajes los vivan. Por eso, la verdadera huella de un escritor de literatura, al abordar esos temas finitos, radica en darle nueva forma a los temas esenciales, como la muerte, el amor, la amistad, la venganza, la locura, por ejemplo. Cada autor o autora con su manera de moldear las subjetividades de su obra, esas decisiones de cómo contar, le dan formas nuevas a la vida y con ella a las metáforas que la constituyen de acuerdo con unas coordenadas sociales y culturales específicas.

Lo que entonces es la etapa de construcción de una obra, de la toma de decisiones de un autor que elige unas maneras de contar, es a su vez lo que hace a la literatura un campo infinito de posibilidades. Porque en esas decisiones, en ese actualizar las problemáticas humanas y descubrir formas que den nuevos conocimientos a los lectores sobre lo humano, surge la inmensa variedad de la literatura. Podríamos decir que la literatura es como un caleidoscopio en el que las piedras del artefacto serían las pocas metáforas y que cada autor las reacomodaría, como en cada movimiento del caleidoscopio, para contar una nueva historia. Así, es posible crear la literatura, multiplicidad de historias que se hacen infinitas.

La queja de Almudena Grandes, su incomodidad con los críticos, es en el fondo uno de los más grandes sueños de quien escribe: que la forma, su aporte más significativo a la literatura sea entendido y vivido por los lectores. Es decir, una forma de leer que reconoce en el gesto literario las decisiones estéticas que delimitan, moldean, transforman lo que es el material de una anécdota en una obra literaria. Es reconocer el tejido ideado y puesto en el papel de un autor o autora, y que deriva en el encuentro con una novela o un cuento, en el caso de la narrativa.

Desde mi perspectiva, la lectura que genera la formación de la escritura creativa debe abordar este sueño. La lectura que hacemos desde la visión de un taller literario llega al lugar máximo de ese sueño que tendría alguien que escribe. Porque vemos los textos desde las apuestas de alguien que ha inventado una estructura, un manejo del tiempo, una construcción de la historia, un manejo de la atención para que nosotros como lectores vivamos una experiencia significativa con la literatura. Los estudios literarios evidentemente ya han dado una serie de pasos en ese sueño o en ese tipo de lectura. Porque los estudios literarios han generado una lectura que da cuenta del encuentro mágico entre la forma y el contenido, entre el qué y el cómo. Pero, de alguna manera, los estudios literarios han dado también una serie de pasos hacia la objetivización de ese tipo de lectura, y por eso estudian el texto como algo aislado de quien lo escribe, como un producto terminado. Los estudios literarios como campo de estudio y las formas de escritura crítica, buscan encontrar, de alguna manera, esas reglas de funcionamiento del texto, la apuesta 
del cómo, pero aislándolo de la existencia de las decisiones previas de los autores a la existencia misma del objeto de estudio.

En los talleres de los programas de formación en escritura creativa, lo que hacemos es dar un paso atrás. En el papel de la lectura dentro del aprendizaje de la escritura creativa, hacemos un retroceso porque nuestra principal pregunta es cómo y qué decisiones tomó la persona que escribió este texto antes de escribirlo, para escribirlo. Es un ejercicio que intenta reconstruir las motivaciones, las premisas y las decisiones de los autores, basado en los textos mismos y las declaraciones que algunos autores han hecho sobre sus procesos de creación. Cada vez que en el taller leemos un cuento o una novela y cada vez que un grupo de estudiantes de escritura creativa lo discuten, estamos preguntándonos qué decisiones se tomaron, y de esas decisiones cómo se llega a ese texto final que enfrentamos. Vamos buscando las ideas, la trama, y las tareas previas que el autor o autora tuvo que hacer en aras de descubrir su génesis, la etapa previa, eso que Almudena Grandes llamaba etapa de cuaderno.

La definición de la estructura, de la tensión narrativa, diferenciar si es novela o cuento, construir personajes, definir formas de uso del lenguaje, manejos del tiempo. Y luego hacemos también la mirada al tex to terminado, como los estudios literarios y la crítica, y así se convierten en dos lecturas complementarias. Una lectura más intuitiva, que se adentra en la génesis del texto y otra más basada en el resultado final que es el texto mismo. De hecho, yo tengo la sensación de que cuando los estudiantes de los programas de literatura con énfasis en crítica se apropian de la forma de lectura de la escritura creativa, junto a la lectura crítica, son mucho más eficaces como críticos.

Miremos entonces cómo es la lectura quien quiere escribir ficción, que reconoce en el texto su existencia previa, es decir, como lo llama Isaías Peña (2010), el texto inexistente. Todo texto tiene un génesis, un lugar de inexistencia antes de ser lo que nosotros leemos. Un escritor o escritora piensa una historia, una anécdota o una imagen con la que va a construir el texto literario. Luego, debe elegir una tensión narrativa que le de valor a esa historia, anécdota o imagen. Después, tendrá que definir por dónde empezar, crear una estructura temporal para narrar, y ahí sí estará en posibilidad de empezar a escribir. Además, ha construido el mundo previo del personaje, lo conoce, lo ha visto moverse por el mundo aún antes de empezar a escribirlo, a nombrarlo. Se ha hecho preguntas sobre el tema, los personajes y el mundo que lo rodea. Habita el cuento o la novela desde antes de escribir. Interrogamos pues, con más lentitud, cuáles son las decisiones que ese autor y autora tomó para construir el texto.

Para ejemplificar los pasos de esa lectura, voy a usar el cuento Emma Zunz de Jorge Luis Borges. Iniciamos pensando cuáles pueden ser las premisas de donde surge el texto; esas preguntas que van llevando a quien escribe a generar una historia, a descubrir en ella si es material de un cuento o una novela y cuál es la tensión que debe desarrollar. Borges quiere escribir un cuento, lo sabe por el tipo de giro que quiere dar sobre una premisa general; la venganza perfecta, es decir un crimen que no redundará en juzgar a la persona que lo comete. Luego, buscamos tras el texto, ya literario, la anécdota completa, el universo de continuidad de la vida de sus personajes en el que el escritor entra a buscar la tensión. Emma es hija de un prófugo, sabemos que hay una historia desde la infancia de ella en relación con el padre y la madre. Sabemos también que el padre ha huido y ella se empleó en una fábrica que pertenece a uno de los que inculparon injustamente al padre; luego, nos enteramos del suicidio del padre, y sabemos que se tuvo que cambiar el nombre; $y$, finalmente, asistimos a la venganza que la protagonista planea y acomete. Hacemos todo esto porque nos es muy importante conocer el mapa general que subyace a la tensión 
literaria. Dicho de otra manera, buscamos todo aquello que el escritor sabía previamente a una historia, la vida de los personajes, el contexto cultural, social e histórico en que suceden los hechos y demás elementos de la composición, que luego han de ser usados en función del hecho literario: el gesto de novela o de cuento.

Asumimos que el autor ha tomado decisiones estructurales previas, que determinan el texto que leemos y que hace parte de lo que toda persona que escribe debe ir determinando para componer un texto. Escoge una tensión para narrar y una estructura. En el cuento de Borges, vemos que el autor decide que lo que debe contarse son solamente los tres días que dura la planeación y concreción de la venganza. La información adicional que venía de la anécdota general será usada cuando se haga necesario durante el desarrollo de esa tensión.

Le preguntamos al texto las apuestas de lenguaje usadas para narrar la historia. ¿Quién cuenta, desde qué manera de hablar? Es un lenguaje que busca el realismo, la fantasía, lo barroco, lo minimalista. En el caso de Borges, es un narrador realista que, desde una perspectiva muy cercana a la protagonista, nos va contando las acciones que realiza para llegar a la venganza soñada.

Luego, le preguntamos al texto cómo fueron construidos los personajes. ¿Qué informaciones del personaje se nos entregan? ¿Qué tanto construyó el autor el pasado de esos personajes y qué tanto ese pasado entra en la historia? ¿Cómo densificó al personaje, a través de qué elementos, como sensaciones, pensamientos, miedos, sueños, obsesiones? En el caso del cuento de Borges, nos permite conocer las emociones que vive el personaje y la conocemos en la medida en que va contando la venganza. Sabe de ella situaciones del pasado y las trae en la medida en que la historia, la tensión, lo va requiriendo.

¿Cómo llega a definir el tipo de narrador que usa en la historia, qué límites impone a la narración haber elegido ese narrador y cómo sería la historia si fuera contada desde otra voz, otra subjetividad? ¿Qué motivos pudieron haber llevado a ese escritor a optar por dicho narrador? Siguiendo a Borges, podríamos suponer que usa la tercera persona para mantener cierta distancia con el personaje, para administrar mejor los silencios que el plan debe mantener, para que el giro final de la historia no se revele antes de tiempo.

Interrogamos al texto como si fuera inexistente, en las decisiones que tomó el autor antes de empezar a escribir. Y le preguntamos también qué estructura temporal es usada y para qué el autor usó esa estructura. ¿Desde dónde se cuenta la historia, cuento o novela, mientras suceden los hechos, cuando están a punto de suceder los hechos o recién sucedidos o tiempo después de que sucedan? En el caso de Borges, vemos que los cuenta mientras sucede la venganza.

Y esta decisión marca qué manejo de los tiempos verbales y del presente narrativo le impone a la narración. Qué manipulaciones del estado de ánimo del lector quiere hacer ese texto al iniciar por una u otra arista de la historia. Borges nos muestra que Emma recibe la noticia de la muerte de alguien que no sabemos quién es; en seguida, nos lleva a ver la tristeza y después entendemos que era su propio padre que se había cambiado el nombre. ¿Qué preguntas quiere que el lector se vaya haciendo a lo largo del camino? ¿Dónde quiere ubicar al lector en relación con el manejo de la información, quiere hacernos lectores cómplices, detectives, enamorados? ¿Quiere que compartamos el lugar de enunciación del narrador y la información que tiene o la de algún personaje, o quiere que sepamos más que todos los personajes y así 
lamentemos el destino fatal que les va a llegar? En el caso de Borges, nos ubica afuera de las reflexiones del personaje, vemos que tiene un plan, pero lo ejecuta sin explicaciones a los lectores. Solo vemos sus acciones y, poco a poco, descubriremos que la venganza se lleva a cabo, pero, y ahí radica el giro del cuento, que no es perfecta como la soñaba Borges y Emma, porque en el último instante comete un error, no le dice por qué lo está matando.

Dicho de otro modo, la lectura que hacemos pensando en escribir, desmenuzando hasta el fondo las coordenadas que permitieron la existencia de ese texto que leemos, reconoce que un texto literario guarda las claves de cómo fue escrito. Por tanto, una persona que quiere aprender a escribir, encuentra soluciones a problemas técnicos para crear una novela o un cuento, en esta manera de leer. Descubre en esta forma de lectura, eso que hace un rato veíamos como la "etapa de cuaderno" de Almudena Grandes. Aprendemos así, qué asuntos tuvo que pensar el escritor o escritora para llegar a ese texto que tenemos en la mano. Vemos el tejido que dio lugar a ese texto y cómo el tema fue desarrollado desde unas apuestas estéticas que son, finalmente, la gran apuesta de cada escritor.

Entonces, la lectura del que está creando es una lectura que se enfrenta a tomar decisiones para escribir. Tiene que elegir si el material de sus preguntas, los temas o imágenes que quiere contar, son para un cuento o una novela. Debe descubrir la historia amplia de los personajes, para encontrar qué parte de esa vida es la que requiere la tensión narrativa para ser contada. Ve en la maestría de los textos literarios, las vacilaciones de un creador, la toma de decisiones, y de ahí aprende y soluciona sus propios textos. Cada vez que un autor tiene un cuento o una novela por contar, ha resuelto muchas de las preguntas que le hemos hecho en la lectura al texto. Y tratando de develar cómo contarla, encuentra en sus lecturas previas posibles soluciones para empezar a escribir.

Entonces, en esa interrogación que el lector-escritor está haciendo a una obra que ya sido creada previamente y en las claves que encuentra de cómo ese otro creador creó su propia obra, aparece una nueva manera de leer. Una lectura que es un gran aporte que está haciendo la escritura creativa como forma de aproximarse a los textos literarios para que aparezcan las enseñanzas y las soluciones, para que alguien más escriba literatura. Y en esa lectura se vislumbra el gesto más puro de quien lee, la definición de qué es leer y escribir; un ser que se enfrenta a la vida para contarla con las diversas herramientas de la literatura. Un ser que entiende que la literatura de ninguna manera está enseñando algo moral, que más bien la literatura lo que hace es darle forma a la vida, es robar de la vida para contarles a los lectores cómo son las cosas en cada época. Un ser que intenta mostrar aquello que no está en lo evidente, porque de alguna manera lo que es más importante en la literatura es que sea una forma potente de conocimiento de la vida, un gran conocimiento que la desborda, la explora y reconoce las formas en que la vida se está transformando. Esto es algo que busca un escritor y que, por momentos, se les escapa a los críticos.

Esta manera de leer evidencia cómo el mundo se transforma a través de las formas en que está siendo contado, es decir, que la lectura del creador permite reconocer dónde y cómo los textos logran revelar, resignificar, reinventar la realidad. Leyendo así, lo que nos estamos dando cuenta es que la literatura no es el lugar donde se enseña, donde se moraliza, sino el lugar donde los seres que son creados por un escritor o una escritora habitan la realidad. Un espacio donde se habita el mundo y se muestran los sistemas morales, los sistemas de pensamiento, las formas de comprensión del mundo. En ese lugar de la lectura, como lectores y creadores, entramos a universos que nos hacen habitar diversas realidades, allí somos partícipes de ese universo que se construye con decisiones técnicas, con juegos del lenguaje. Los 
lectores y escritores somos seres creados por la escritura. Somos seres arrastrados a la dicha de descubrir los mundos que surgen de las múltiples decisiones tomadas por un autor, de las que nos hace partícipes para que vivamos la experiencia de habitar el mundo que ha escrito.

\section{Referencias}

Borges, J. L. (1996). Elogio de la sombra. Buenos Aires: Emecé.

Borges, J. L. (1992). El Aleph. Buenos Aires: Emecé.

Peña Gutiérrez, I. (2010). El universo de la creación narrativa. Bogotá: Ediciones del Huaco. 